\title{
ICT-based reforms in local government decision-making in the gram panchayats of Kerala
}

\author{
Alex. K. Thottunkel \\ Sibi Varghese Kuppathanath
}

\begin{abstract}
The beneficial impact of computerisation can be felt in all elements that contribute to decision-making in panchayats in the state of Kerala. However, even though computerisation is bringing about immense improvements compared to traditional administrative practices, but scope still remains for further improvement. Instead of the 'as it is' computerisation that is mostly carried out a process based approach is needed.
\end{abstract}

Key words: local government decision-making, office procedures, workflow automation, e-governance, panchayats, local government reforms, 'file noting', file verification, file movement, Kerala, government process re-engineering, GPR, process improvement.

\section{Introduction}

Panchayats are the local democratic institutions in India, which provide a range of functions from public works to welfare and development programmes. They make decisions on many issues which profoundly affect local citizens' lives.

To ensure validity, decisions need to be underpinned by analysis and synthesis of information; and for this to happen the information must flow through a sequence of verification, validation and authorisation steps which constitute the decision-making process.

(C) 2015 Alex. K. Thottunkel and Sibi Varghese Kuppathanath. This is an Open Access article distributed under the terms of the Creative Commons Attribution 4.0 Unported (CC BY 4.0) License (https://creativecommons.org/licenses/by/4.0/), allowing third parties to copy and redistribute the material in any medium or format and to remix, transform, and build upon the material for any purpose, even commercially, provided the original work is properly cited and states its license. 
The routine administrative procedures in any panchayat includes:

- Handling the various types of communications in the panchayat;

- Recording of the communications in registers including the generation, up-keep and storage of generated files;

- Movement of file or any other communication from one official desk to another;

- Verification and queries about the issue on the communication/file;

- File Noting or the observations made on a file by the official, and

- Rule bound decision-making based on notes, queries, verification, precedents and discussion. T

This article explores how reforms based on ICT can improve activities related to procedural decision-making. The first section describes current reforms in decision-making procedures in Kerala ${ }^{1}$ panchayats using ICT (information communications technology). The second section assesses the potential for ICT, together with a process-based approach, to further improve decision-making by panchayats.

\section{ICT-based Reforms in Office Procedures}

\section{Enabling tasks: communications received and generated}

Communications - the major input for decision-making - can arise from internal or external sources, and can be oral or written. Communications received trigger the workflow that initiates the decision-making process. Typically, communications received are acknowledged, converted to written form, numbered, registered and stored in files.

As a file passes through each stage of processing its information is entered in various registers or databases. In a manual workflow system, communications are liable to be missed, file-processing incomplete and information lost if files are not numbered or registered properly. Once a file reaches a decision-making authority, a draft response with details of the issue, proceedings and decision is made for final dispatching. Drafting is a timeconsuming process, especially if corrections need to be made, which increases workload in an environment of limited resources.

Kerala panchayats have increasingly opted for workflow automation to solve these problems. In a computerised workflow system all incoming communications are automatically numbered and registered, thus improving retrieval and ensuring certainty in the delivery of the service output without the possibility of any missing communication, incomplete processing or lost information. Drafts can easily be sent between staff for

\footnotetext{
${ }^{1}$ The state of Kerala, located in southern India, is known for its comparatively high human development index and effective devolution of functions, funds and functionaries to local governments. Kerala opted for panchayat computerisation developing and implementing a series of applications through its dedicated agency Information Kerala Mission.
} 
corrections, and templates can be used for frequently sent communications. As all communications must be digitally recorded, a list of the day's incoming communications is available to managers, helping to reduce delays, avoid corrupt practices and determine the nature of frequently received communications. The list of pending communications can be easily seen, and the location of any bottlenecks in workflow can be detected, making correction easier.

Additionally, inter- and intra-office communications have improved considerably since the advent of mobile SMS (texting) and email. For example, mobile phone numbers collected from service users are used to request additional information, to inform them of the status of an application, or to send them details of welfare programmes.

\section{Box 1: Improvement in communications at election time}

Staff at the office of the Deputy Director of Panchayats (DDP) in Wayanad harnessed the power of ICT to speed up the communication of circulars during the 2010 local elections, which enabled them to take immediate action on the huge number of circulars received every day at this time. The DDP Office started its own blogspot, on which the circulars were posted (http://ddpwayanad.blogspot.in/p/election2010.html). The posting of a new circular was notified to the mobile phones of all relevant officials at the many block, district and grama panchayats which use SMS services. As well as facilitating a speedy response to the circulars, there were also savings in travel expenses and staff time, enabling staff to be redeployed to other urgent duties.

\section{Information recording}

Recording helps in storing, retrieving and tracking information that has been received, sent, processed or generated. To retrieve the right record, an indexing/classification system is used which indicates the record's exact location in the main registers. In a paper-based system this generates innumerable paper files and many book registers, which are difficult to maintain. The 130 or more books and registers used in every panchayat contain immense amounts of non-sharable common information. Even if records are maintained, they often have pages missing or incorrect entries. Most column entries in book records are inadequate to identify misuse if it occurs. Panchayats also manage their paper-based records poorly, leading to worse services for the public and audit complaints about missing files and records.

Workflow automation software populates the registers automatically, and retrieves files faster due to its automated indexing and faster recall of data by searching for any subject-related relevant word. It also eliminates the need for manual movement of files. For example, Kerala's custom-built software for direct tax collection application, decision support application and civil registration application all query and populate the digital versions of their file registers automatically whenever a transaction takes place. Once collected, data can be shared across functions and departments, thus reducing the need for repeated data collection, saving data 
entry time and avoiding duplication. Once an entry is made and the database of the records populated, corrections to the database can only be made after a very strict authentication procedure by an authorised committee. This means that making fraudulent changes - which can be inserted by anyone in a manual record is much harder in the computerised environment. The system also has much better accountability and transparency due to automatic procedures such as role-based individual authentication mechanisms, adequate appropriate permissions, automated creation of event logs, and traceability of unauthorised attempts to manipulate the system. Queue-jumping or favouritism can also be eliminated when workflow automation software is used in the front office. ${ }^{2}$

The new 'e-Forms' project represents a major advance in information recording, as applicants can now fill in relevant information on a form themselves, either from home or by attending a common service centre for assistance, before it is submitted to their panchayat for processing. For a nominal fee, those who cannot use computers are provided with an assisted service for filling by the Akshaya CSC's. Akshaya CSC's are public private partnerships located throughout the State, so many services can be accessed without visiting the government offices.

\section{Box 2: Improvement in information recording with e-filing}

The application form for marriage registration and a marriage certificate can now be filled in by the applicants themselves on Kerala's Local Self-government Department website. All panchayats share a common marriage software application module, which is connected to the state datacentre. By creating a username and password, applicants can fill in the form and file it along with scanned copies of photographs and proofs of identity. Using the same user credentials, the data can be edited later if needed. A printout of the final e-form can then be submitted to the panchayat at the time of marriage registration. The registration unit clerk, who will have an official login, will verify the data entered against the proofs of identity brought by the couple and then forward the application to the secretary. The secretary is able to click on the 'approval' button in the application, print out a marriage certificate, sign it and hand it over to the couple. A newly-wed couple can now get a valid marriage certificate in one hour, compared to the previous wait period of a couple of days. Once the data is sent to the state datacentre by the panchayat, the certificate can also be downloaded from the Local Self-government Department website. In addition to reducing data entry time and overall processing time for the panchayat, because the data is entered by the applicants themselves there is less likelihood of errors in the certificate or delays caused by submitting the wrong documents for verification. For applicants who prefer, staff are available at panchayat common service centres to help with the process of e-filing.

\section{Movement of information}

In a manual workflow system, information moves from one desk to another for collection and validation, verification of its accuracy, or to secure management approval. The need for management approval can cause delays. Delegation of authority is discouraged and multiple approvals are encouraged, in an effort to improve

\footnotetext{
${ }^{2}$ Physically, panchayat offices in Kerala are now divided into a front office, a main office and, in principle, also a records section.
} 
accountability - but this increases file movement. Files can be held up at any stage due to lack of information, re-verification, re-approval, or re-working.

These issues are avoidable in a computerised environment, where information is easily available and clerical errors are reduced, thus increasing the scope to make informed decisions. Multiple points of approval, which create delays and water down responsibility, are no longer needed due to a better audit trail. As information sufficient to take a decision is available at any point - including at the point of initiation such as the front office - services can be delivered within the time stipulated in the citizen charter. Each paychayat adopts a citizen's charter which sets target service-delivery times.

\section{Box 3: Improvement in delegation resulting in reduced file movement}

In previous manual workflow systems, higher authority approval was needed even to issue a simple certificate. This practice dated from colonial times but has now been discontinued thanks to computerisation and the move to a 'single window' front office system. Now, the availability of sufficient information at the front office itself means that front office staff can initiate the approval process for many certificates.

\section{Core Decision-making Tasks}

\section{Official verification and/or queries about information}

In a manual or partially computerised workflow system, applications are verified at two levels. When an application is received it is checked for correctness, completeness of information, general conformation to rules and conditions, and the authenticity and sufficiency of any attached documentary proofs. This first level of verification can prevent identity theft for obtaining benefits, ensure that no forged documents are submitted and confirm that sufficient documentary evidence is provided, as required by relevant rules. However, this work is very time-consuming and the lack of sufficient resources creates delay from the outset of processing. At a second level, the information gathered is scrutinised and its details are checked to make sure it is error-free and genuine. If needed physical field verification is carried out to authenticate any claims made by the applicant.

\section{Box 4: Improvements in verification}

With e-filing, requirements of initial primary verification such as correctness, completeness and conformation are addressed. The specific function's application package itself crosschecks information against the set conditions. Repeated verification of the same issue is not needed, because the first verification (effectively a 'one-time' verification) is recorded as authentic base data.

\section{Summarising information with 'file noting'}

File notes are observations made by officials as a file moves up the hierarchy. Notes may contain information 
about verification, whether scrutiny has revealed some information which breaches existing rules, rules related to the particular issue, pros and cons, the history of the case, chronological summaries of communications received, answers to queries, responses to instructions, and suggestions as to whether an issue should be accepted/rejected/modified/postponed, etc. File notes should validate the information supplied, based on logical reasons supported by evidence, and help the final decision-making authority to arrive at an informed decision.

Notes reveal the decision-making processes in a file: how a decision was made and what led to a particular decision. Unlike a private business, where noting is very rare and the output of a decision is usually an immediate letter, memo or instruction to a subordinate, the government is answerable to the public, so each step and the reasons that lead to a decision must be recorded (Gadkari 1998: 35). According to the state-wide Kerala Manual of Office Procedures, a clerk or junior supervisor is not permitted to add any opinion, instructions or recommendations and, once made, notes cannot be deleted by superiors. Despite this, a common problem is for the clerk who makes the first note on the file to set the direction of decision-making; either by limiting the facts related to the previous precedents, or by writing an initial note which favours or disfavours an applicant, based on the clerk's subjective decisions.

\section{Box 5: Improvements in 'file noting'}

Computerisation has helped reduce the time required for noting, since rules, precedents and similar cases can be referenced quickly. Notes are permanently stored and easily retrievable, making it easy to see who set the direction for a particular decision and thus ensuring accountability. Bulky paper-based case files can now be entirely discarded for those processes which are computerised.

\section{Arriving at the final decision}

Routine decision-making is mostly based on procedures, rules, verifications, existing Orders and precedents. If a non-routine situation arises and precedents or standardised procedures are not relevant or appropriate, the file is referred up the management chain or, depending on the issue, may even be sent to the panchayat committee. However, decisions are often deferred by officials, ${ }^{3}$ for fear they may later be held responsible for any procedural lapses even if there is no personal gain involved. Once a decision is made it needs to be authenticated by an authorised signatory, normally the panchayat secretary.

\section{Box 6: Improvements in procedural decision-making}

Computerised workflow applications enable an authorised signatory to check whether verification is complete and the approval of subordinates has been given. The signatory can also go through any file notes before making the final decision. This enables informed, fact-based decision-making drawing on timely, detailed, accurate and precise information. Decisions cannot be kept on hold, as the public can check progress of an application through the relevant website or at an external kiosk. This promotes speed as well

\footnotetext{
${ }^{3}$ Project delays caused by bureaucratic fear of decision-making often lead to cost overruns in implementation. Reports based on data collected by the Ministry of Statistics on mega-projects found that cost overruns were equal to the total budget of the education and rural development ministries put together (Yadav 2012: 1).
} 
as accountability and transparency. Subjective decisions and personal preferences are less likely to influence any decision, as standardised pre-set steps have to be followed. In a computerised system, who did what is easily traceable, and restrictions can be placed on each login to prevent unauthorised alterations. In an unalterable, secure and reliable computerised system it is easy to trace the logic and reasoning that have led an honest official to take a particular decision, thus freeing them from liability.

Other than routine procedural decisions made by officials, there are also decisions made by the periodic panchayat committees and grama sabhas. To arrive at sound decisions these bodies need to know what the issue is, what the possible courses of action are and what decisions are legally possible.

The input for elected representative committee decisions comes in the form of agenda notes prepared by officials and the advice given by the secretary on statutory rules, procedures and laws. Grama sabhas, based on the principles of direct democracy, are made up of ordinary citizens from a panchayat and have been given extensive powers by the state. Panchayats' annual budget, budget instructions, draft development plan and beneficiary list must be submitted to the gram sabhas. Computerisation has considerably eased the workload of the meeting. It helps the secretary access accurate information to submit to committee and grama sabha meetings, prepare meeting agendas, and draft and circulate minutes.

In the past, numerous rules and complicated manual procedures kept both the public and elected representatives in the dark about office procedures. The elected panchayat president is supposed to lead on all decisions except those that relate to the statutory powers vested in the secretary or other officials. The president can also access official information provided it is requested in writing, a receipt is given and the information is returned. It is also mandatory that communications sent from the panchayat should be approved by the president. Elected representatives also have the right to view records during working hours. However, in manual systems information access is limited due to system limitations and procedures, leaving officials in control of decisionmaking, since they entirely control information flows.

\section{Box 7: Improvements in the ownership of information}

Most government Acts and Orders are now readily available on the Kerala Local Self-Government Department website. In a digital workflow system, complicated manual methods are demystified and simplified, allowing the public to monitor the functioning of their panchayat or track an application as it works its way through the system. With computerisation, the power of elected representatives in decision-making processes is greatly enhanced as the president can view all official records. Relevant emails can be routed electronically for his or her approval ${ }^{4}$. The president and other elected representatives can also easily scrutinise files or even check the details of a pending file. These vast improvements in access to, availability of, awareness of and usability of information for elected representatives are transforming decision-making, which is no longer predominantly controlled by officials. Computerisation changes the ownership of information and thus democratises decision-making processes.

\footnotetext{
${ }^{4}$ Under Government Order no. 1838/2012/LSGD dated 3 July 2012, the president and vice-president of a panchayat are to be officially provided with desktop systems in their office.
} 
In the past, with paper-based systems, macro-level tracking of the many hundreds of panchayat projects across the state was not possible; nor was aggregated current data readily available for planning or monitoring at any level (panchayat, block, district or state). Unreliable and inaccurate reporting systems were the major reasons for these failings.

\section{Box 8: Improvements in planning and monitoring}

Macro-level financial decision-making - ie at state level - is also improved, thanks to the availability of accurate, precise and timely information reports compiled at each level of government. Computerisation not only eliminates previous delays caused by having to sending a file to the finance department for approval, but has also made budgeting and fund allocation more realistic. In a totally integrated computerised environment it is possible to make highly informed financial decisions after calculating and considering impacts such as the capital cost of a development programme or any revenue deficits the programme will create in its lifecycle. Social cost-benefit analyses can also be conducted with the help of a well-maintained database.

As an example, most hospitals connected to the state computer network are able to easily generate and send their mandatory monthly birth and death registration reports, broken down by panchayat, to first the district registrar and subsequently the state chief registrar. This accurate and timely demographic information can then be used to prepare realistic state- or national-level plans.

Computerisation also allows the development of web-enabled systems that can be viewed in real time by all relevant stakeholders, even if geographically distant, to help them make accurate and timely decisions - without the need to generate periodic reports or create duplicative files related to the same issue in each department. Web-enabled applications can provide instant panchayat-level information to statelevel elected representatives ${ }^{5}$ or top-level executives.

Now, however, for each panchayat using Kerala's Sulekha ${ }^{5}$, the custom-built software for 'Project Plan' formulation and monitoring application, the planning process has become less time-consuming and resourceintensive. Plan formulation, submission for approval, revision, expenditure monitoring and tracking, report generation and publishing are all enabled by a customised application package and dedicated application website.

\section{Improved Prospects in Decision-making with ICT-enabled Reforms}

A few of the totally process re-engineered web-enabled services such as issuing certificates are making life easier for the citizens, as some of the certificates can now be downloaded directly from Kerala's Local Self Government Department website. 'Re-engineering seeks breakthroughs not by enhancing existing processes but by discarding them and replacing them with entirely new ones' (Hammer and Champy 2001: 52). The scale of this change gives a sense of the immense gains that government process re-engineering ${ }^{6}$ (GPR) can bring. The

\footnotetext{
${ }^{5}$ Members of the state legislative assembly can view the development and implementation status of plans at all 998 panchayats across the state using 'Sulekha', a custom-built software for plan formulation and monitoring application.

${ }^{6}$ See for example the Knowledge Commission's Letter of Recommendation to the Prime Minister, and the Eleventh Report of the Second Administrative Reforms Commission (Promoting E-governance the Smart Way Forward, 2009), which both endorse implementation of
} 
administration gains through improved process efficiency and efficient use of resources - resources which can be productively redeployed to alternative priorities such as rural development or welfare activities. Citizens benefit immensely, for example from round-the-clock service availability over the internet, the avoidance of rent seeking, and the savings in working hours earlier lost due to frequent visits to the panchayat office. This total reengineering of service delivery is possible only by harnessing advances in technology. 'Without information technology little re-engineering can be done' (Hammer and Champy 2001: 5). In Kerala, delivery procedures for more services need to be thus re-engineered to generate favourable outcomes for the state's major stakeholders:

\section{Box 9: Improvements in office procedures using new front office system}

A citizen satisfaction survey on service delivery conducted by the Kerala Institute of Local Administration using the Citizen Report Card method (Balan 2006: 212) painted a dismal picture of panchayat offices before the introduction of the 'single window' front office system. Common complaints were: a lack of computerisation, delays in processing files, staff absences from the panchayat (meaning people had to visit the office many times), poor employee attitudes, and overly complex office procedures. The front office system now in operation in almost all panchayats has radically changed the way these offices function. It introduced a 'single window' approach with associated benefits such as defined service outputs, minimal official interaction and limited need to know at which desk the file is pending. A first-come, first-served system was introduced, alongside specific role-based responsibilities for staff and an orderly workflow spanning the front office and main office. A shift in perception towards the citizen as a customer to be served is also noticeable, evidenced by the introduction of a waiting lounge and facilities for the convenience of the citizen.

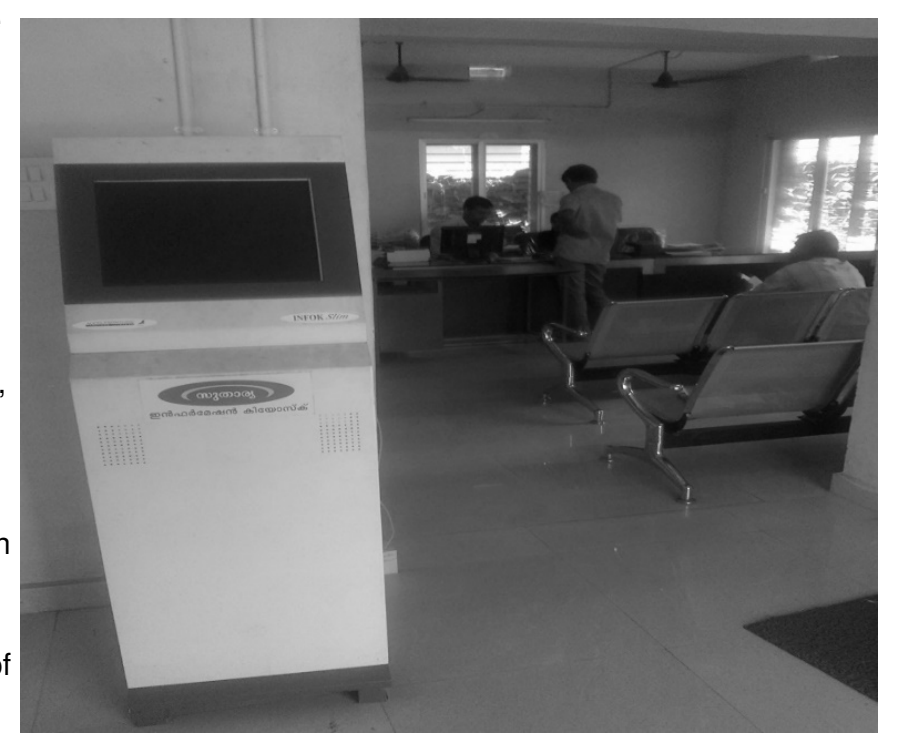

Even in cases where data digitisation is not complete, or services cannot be delivered over the web, existing manual processes still offer huge scope for process improvement. In Kerala one of the few major attempts to do this has been the establishment of a 'single window' front office system, under Government Order GO 123/2009/LSGD in 2009.

On a less positive note, other than the recent establishment of the front office system, most individual processes which have existed for decades have been computerised without any substantial process improvements. Though many manual workflow issues could have been easily rectified with a properly redesigned or thoroughly re-

the concept of GPR to improve existing archaic processes. 
engineered computerised workflow, the computerisation of existing processes means that inefficiencies and corruption loopholes associated with the manual system still remain.

Just as computerisation speeds up processes, computerising an existing system without proper re-engineering speeds up and multiplies corruption practices (Caselay 2004). Jonathen Caselays study of land registration in the state of Andhra Pradesh without proper process improvement in the year 2003 endorses what Micahel Hammer and James Champys states "merely overlaying new technology on old ways of doing business achieves very little" or "automating a mess yields an automated mess" (Hammer,M and Champy 2001;3-6). A similar study by Jonathen Caselay on the Department of Registration and stamps in Maharashtra (Caselay 2006) depicts how the process re-engineering effort of Dr Nitin Kareer the newly appointed administrative head of the registration department, revamped the whole system with the support of the political higher ups. Though computerisation was initiated in 1998 the sub registrar offices were epitomes of corruption, with enormous discretion in document registration and value determination, sub registrars had even the right to decide when to return the document to the citizen. Without clear cut service standards to fix accountability it was normal for the document processing time to range from weeks to years. Despite the challenges by 2002, taking bold steps Dr Kareer studied the existing process, designed an entirely new process, ensured that the software is modified to automate the new process redesign and improved service delivery facilities were put in place, which resulted in the delivery of documents which took years, to be processed within 30 minutes, and a drastic change from a culture of arrogance to politeness and corruption to become an old story. To ensure the sustainability of the changes, before he left the office Dr Kareer even got ISO 9001 certification for the department. Political will keeps many of the subversive nexuses in control and overcomes the institutional inertia to continue with the reform efforts.

In general just computerising an existing manual process 'as it is' is not enough for it to qualify as 'egovernance'. This is because an e-governance system (unlike computerisation of manual systems) should be efficient and effective, generating outcomes that are valuable to the citizen. Each and every step in the manual decision-making process should be checked for its necessity and redundant steps eliminated before its automation. An organisation/sector wide process based rethinking is also needed as some process crosses many departments weakening accountability and causing hazzles to the citizen who is forced to visit many offices to avail a single service ${ }^{7}$. Once a new system is established it should be refined using the principles of continuous improvement, To sustain the beneficial changes from the redesigned process and institutionalise it standards such as ISO should be utilised. In effect this also calls for a re-look into every computerised process in use.

7 The Government Process Architecting Framework Report 2012 published by the Department of Administrative Reforms \& Public Grievances, Government of India calls for an organisation-wide review covering strategy, structure, processes and technology to bring standardisation and consistency across the organisation. 
Any change in service delivery affects entire rural communities, considering the range of services that a panchayat provides. Manual systems based on the Weberian hierarchical model evolved to suit the needs of the influential stakeholders, who are effectively 'caretakers' of the systems rather than the actual 'process owners' who ideally should be the local citizens. E-governance creates an environment in which panchayat processes can be moulded to benefit and prioritise the needs of its main stakeholders: the rural population. Mere process automation without improvement is just crude computerisation and could never be termed e-governance. With true e-governance major gains in desirable outcomes for ordinary people can be achieved alongside maximum gains in process efficiency. But this requires an enabling environment which is made up of long-term unyielding political support, attitudinal change among the influential stakeholders, change management initiatives to overcome resistance, and a strong legal framework that authenticates and sustains the reforms.

\section{Conclusion}

ICT is driving radical changes in panchayat office procedures. The administrative benefits (reduced effort and time) are evident in those tasks that have already been computerised, whether these be core tasks or the enabling tasks needed for decision-making. Digitisation and automation also promote good decision-making in panchayat offices, due to the ready availability of sufficient and accurate information. Democratisation of the decision-making process is also apparent, since computerisation enables democratically elected representatives and citizens to have more say in how decisions are made.

The impressive improvements seen in those processes already computerised also indicate the potential for even manual or partially computerised service delivery processes to be enhanced. Services on which people depend can be fine-tuned or even thoroughly overhauled using modern techniques such as incremental process improvement or complete process re-engineering. This will improve both efficiency and effectiveness of outcomes.

Even then, huge scope for improvement remains. Processes should be thoroughly analysed, rethought and redesigned for the full benefits of ICT to be harnessed and the computerised process to merit an 'e-governance' tag. Also, whereas in the past e-governance was associated merely with efficiency gains due to computerisation, it is now clear that its benefits are far wider. As well as providing an opportunity to systematise, standardise and embed better processes, it also engenders effective and desirable outcomes that benefit the real process owner, major stakeholder and ultimate beneficiary of the process: the citizen - for whom the whole governance and administrative system exists. 


\section{References}

Balan PP, 2006. Capacity building for strengthening local governance: The Kerala Experience, Kerala Institute of Local Administration, Thrissur, Kerala.

Caselay J, 2004. Public sector reform and corruption CARD facade in Andhra Pradesh, Economic and Political Weekly, 13 March 2004, pp. 1151-1156.

Caselay J (2006), 'Transforming Service Delivery in an Indian State;Reform at the department of Registration and stamps in Maharashtra',Chand V K (ed) Reinventing public service delivery in India selected case studies, World Bank,Sage

Gadkari SS, 1998. Office Management for Public Administration Principles and Techniques, Concept Publishing Company, New Delhi.

GO (MS) No.123/2009/LSGD Dated 02.07.2009. Guidelines for implementing front office in grama panchayat. Available for download at lsgkerala.gov.in

GO (MS) No.1838/2012/LSGD Dated 03.07.2012. Complete computerization of panchayats - Increasing the number of computers that a panchayat can purchase. Available for download at lsgkerala.gov.in

Government Process Architecting Framework (GPAF) Report, Department of Administrative Reforms \& Public Grievances (DAR\&PG), May 2012.

Hammer M, Champy J, 2001. Re-engineering the corporation: A manifesto for business revolution. Nicholas Brealey, UK

Manual of Office Procedures available at www.keralagov.in

Manual of Office Procedures for use in offices other than the secretariat, Government of Kerala 2005

National Knowledge Commission's Letter of recommendation to the Prime Minister of India available at www.knowledgecommission.gov.in/downloads/recommendations/egovernanceletterPM.pdf

Second Administrative Reforms Commission, Thirteenth Report The Organizational Structure of Government of India, 2009.

Second Administrative Reforms Commission, Eleventh Report Promoting E-governance the Smart Way Forward, 2009.

Yadav Y, 2012. 'Climate of Fear Costs Rs 118 Cr,' Indian Express, 22 October 2012, p .1.

\section{Annex}

\begin{tabular}{|l|l|l|}
\hline \multicolumn{3}{|c|}{ List of Web-based Panchayat Services Developed and Implemented by Information Kerala Mission } \\
\hline Application name & Service Outputs & Hyperlink \\
\hline $\begin{array}{l}\text { Sevana for common } \\
\text { marriages }\end{array}$ & $\begin{array}{l}\text { Common marriage registrations, } \\
\text { certificates }\end{array}$ & http://www.cr.Isgkerala.gov.in/Cmn Application.php \\
\hline $\begin{array}{l}\text { Sevana for births and } \\
\text { deaths }\end{array}$ & $\begin{array}{l}\text { Birth and death registrations, } \\
\text { Certificates }\end{array}$ & http://www.cr.Isgkerala.gov.in/ \\
\hline Sevana for pensions & $\begin{array}{l}\text { Pensioner support services, } \\
\text { information }\end{array}$ & http://www.welfarepension.Isgkerala.gov.in/HomeEng.aspx \\
\hline Soochika & File-tracking information & $\underline{\text { http://www.filetracking.Isgkerala.gov.in/ }}$ \\
\hline Sankhetham & $\begin{array}{l}\text { Building permits issue as per } \\
\text { panchayat rules }\end{array}$ & http://www.buildingpermit.Isgkerala.gov.in/ \\
\hline Sanchaya & $\begin{array}{l}\text { Property tax payments, ownership } \\
\text { certificates }\end{array}$ & https://www.tax.Isgkerala.gov.in/epayment/ \\
\hline Sulekha & $\begin{array}{l}\text { Plan monitoring, formulation and } \\
\text { related Information }\end{array}$ & http://www.plan.Isgkerala.gov.in/ \\
\hline
\end{tabular}




\begin{tabular}{|l|l|l|}
\hline \multicolumn{3}{|c|}{ List of Web-based Panchayat Services Developed and Implemented by Information Kerala Mission } \\
\hline GIS & GIS-based maps & $\underline{\text { http://www.gis.Isgkerala.gov.in/ }}$ \\
\hline Sugama & Public works cost estimates & $\underline{\text { http://www.works.Isgkerala.gov.in/ }}$ \\
\hline $\begin{array}{l}\text { Sankhya for double-entry } \\
\text { accounting system }\end{array}$ & Double-entry accounting systems & $\underline{\text { http://www.finance.Isgkerala.gov.in/ }}$ \\
\hline Sthapana for panchayats & $\begin{array}{l}\text { Employee provident fund details - } \\
\text { panchayats }\end{array}$ & http://kpepf.Isgkerala.gov.in/Contents/Login.aspx \\
\hline Sanchitha & $\begin{array}{l}\text { Electronic legal adviser, information } \\
\text { about Acts, Regulations, government } \\
\text { Orders etc }\end{array}$ & http://lsgkerala.gov.in/sanchitha2/ \\
\hline
\end{tabular}

